\title{
Towards an Integrated MCDM and BSC Method to Support the Digital Transformation Strategy in Railway Companies
}

\author{
Gabriel Nogueira ZANON ${ }^{1}$, Anderson Luis SZEJKA and Eduardo de Freitas Rocha \\ LOURES \\ Industrial and Systems Engineering Graduate Program - PPGEPS, Pontifical Catholic \\ University of Paraná - PUCPR, Curitiba, Paraná, Brazil
}

\begin{abstract}
Digital transformation is now widely discussed and applied in different enterprises and under various organizational aspects. Traditional industries recognize the need to innovate and digitalize their business processes and models. Among these industries, the railway sector presents a vast space for digital transformation. The railway has several operational, regulatory, regional and technological specificities that must be taken into account in the digitalization processes. Given the multiple aspects involved and the transdisciplinarity, the digital transformation strategy and roadmap of companies must be defined in a way that fits it to the corporate strategy, allowing digital transformation program to be implemented effectively, prioritizing internal sectors with the greatest strategic impact, generating greater productivity, business models improvement, security and, above all, competitiveness for the sector. This research aims to propose a model for the definition of the digital transformation strategy in the railway companies using the Balanced Scorecard (BSC) as a tool for strategic organizational analysis and multi-criteria decision-making (MCDM) to define the drivers for digital transformation in the railway. Finally, to demonstrate the proposal, a case study will be carried out at a Brazilian railway company.
\end{abstract}

Keywords. Digital transformation, railway, organizational strategy, transdisciplinarity, BSC, MCDM

\section{Introduction}

Traditional organizations must adapt and embrace change. The digital transformation will not only help to grow but also generate new and better business models creating value for all stakeholders [1]. The success of the digital transformation process requires the organization to develop a series of capabilities that vary according to the business context and the specific needs of each organization. Therefore, the organizational strategy must be adapted to digital reality, by integrating new technologies into the business model [2].

According to [3], strategic orientation is the main determinant and influencing factor for digital transformation. Digital transformation is not a linear process and there are

\footnotetext{
${ }^{1}$ Corresponding Author, Mail: zanon.gabriel@pucpr.edu.br.
} 
different possibilities for the course of actions [4]. Organizations lack strategic clarity, they tend to fail in this round. The organization needs to know what it wants to achieve through the digital transformation process so that it can strategically plan its actions [1] and all efforts must be directed towards the fulfillment of this strategy [3]. Technology has evolved from an active back office to an essential element in building corporate strategy. Therefore, technology and business strategies must be aligned in equal terms, with the output of a digital business strategy [4][5].

Given the importance and urgency of digital transformation in companies, decisionmakers seek to develop strategies that make this process feasible [4]. However, a clear strategic vision is one of the main gaps and challenges faced by traditional enterprises in the face of digital transformation [1]. [4] indicate that at the beginning of the transformation process, companies tend to experiment or react to external changes. Only in a second moment do they carry out adequate systematic planning.

There is a gap in the literature related to methods that help to create a digital transformation strategy integrated with the organizational strategy, based on analytical techniques [6], mainly for service industries. [7] shows a domain of representativeness of studies related to digital transformation in manufacturing, mainly with the expansion of industry 4.0 concepts. Traditional sectors of the economy are also looking for new challenges and opportunities related to digital transformation. Railway companies fall into this type of sector and digitalization is a key point for improving the operational efficiency of rail transport and represent a significant challenge in terms of the theoretical and practical development of solutions for operating conditions and operating specificities of the rail market [8]. In [8], the authors also point out that in the construction of the configuration of influencing factors in the process of digitalization the business models of railway companies, one of the relevant aspects is that the companies strategies presuppose the digitalization of key areas in the coming years and conclude the study indicating the need to expand research related to digital transformation in the railroad to clarify various topics related to the subject, given the inherent complexity of the sector and the dynamics of developing solutions for the digital economy.

A low level of correlation, in the opinion of the consulted specialists, between the digital transformation of the business models of the railway companies and the integration of operational processes is shown [9]. This result does not initially prove the importance of digitalization and its impact on improving the operational activity of the railway companies studied. The authors comment that this result may be surprising in the context of railway operations, which work similarly to an integrated and dependent technical ecosystem of operational sectors (planning, maneuvering, traction, maintenance), but emphasize that the result is possibly due to the low level of technological progress by railway operators and indicate that, in the future, with the implementation of technology and evolution about digital transformation, the level of correlation between digital transformation and operational integration must be improved.

There is a lack related to digital transformation in the railway industry, as well as approaches with tools and methods for creating digital transformation strategies in line with organizational strategies. This article seeks, based on the appropriation of multicriteria strategy and decision-making methods and tools, applied to the creation of a strategy for digital transformation, to propose a method to indicate, among technological elements, those with the greatest strategic impact for organizations, to contribute elements that allow greater clarity to decision-makers in the definition of digital transformation roadmaps. Also, to assess applicability, a case study in the railway 
industry is proposed, specifically in a freight railway, to contribute to the evolution of the modal towards digital transformation.

This article is structured as follows: Section 1 presents a brief review of the literature on digital transformation in the railroad, BSC, and MCDM. Section 2 presents the proposed method integrating BSC and MCDM. In section 3 the application of the method in a case study in a brazilian freight railway industry. Section 4 discusses the applicability of the method and the results obtained. Finally, in section 5 the conclusion of the study.

\section{Literature review}

\subsection{Railway digital transformation}

A brief review of the literature, digital transformation can be defined in general terms as an organizational change, on several levels, which includes the exploitation of digital technologies to improve existing processes and the exploration of digital innovation that can enhance business models [1][4].

A robust and reliable rail system is important to provide high social and economic value [10]. It is a complex market from a legal, regulatory point of view and concerning the division of responsibilities between individual entities, which may vary regionally. The main problem faced by the sector, in many countries, is being competitive to other modes (eg.: road and air) [9]. Greater mobility, productivity, and environmental gains are reflected in the increased use of the railway modal. Therefore, better rail reliability, effectiveness, and efficiency in operational processes are essential. To overcome these challenges, the railway industry needs to develop strategies that allow a transformation of the existing configurations to a digitalized system [10].

Digitalization in the railway industry is a key factor providing opportunities for growth of social aspects that influence the quality of services and operational safety, as well as improving business efficiency and providing a greater competitive and strategic advantage for the modal given the positioning of the sector in the economy digital. The use of technology allows the transformation of resources into economic results and activation of the market and new customers [8].

In this context, [8] point out that service challenges are an important approach, in line with the concepts of service management 4.0. Digital transformation in the railway plays a fundamental role in improving the integration of operational processes, reducing complexity, enhancing efficiency, and reducing costs. Therefore, it represents a significant challenge, as its dynamics must respect important regulatory aspects that involve the railway business model. In this way, digitalization involves the development of organizational, operational, and technical, theoretical, and practical solutions, in a systemic and multidimensional way. The digital transformation in the freight railroad has a broadly multidisciplinary and challenging aspect. This can be seen, for example, in the European Rail industry Freight Agenda (ERIFA), in which 27 technologies were identified in 5 different pillars of improvement: energy efficiency, productivity and capacity, reliability, noise reduction, and the total cost of ownership [8][13][14].

\subsection{Balanced Scored Card (BSC)}

An organizational strategy shows how the company intends to create value for its customers, stakeholders, shareholders [12]. Among the existing strategic management 
models, the BSC is one of the most widely found [13]. The BSC translates the organizations mission and strategy into a systematic framework for strategic measurement and management, holistically complementing the financial performance measurements with measurements of the company's future performance factors plus the assessment of how the organization creates value for customers and how to improve internal capabilities and investments needed to improve long-term performance and competitiveness [14].

Source [12] presents a descriptive framework for strategies for creating value, linked in a chain of cause and effect, containing the following important elements:

- Financial performance: the maximum definition of organizational success. The strategy describes how the company intends to create sustainable financial growth;

- Customer value proposition: the central element of the strategy. Success with customers is the main factor for financial performance;

- Internal processes: create and deliver value to the customer, the good performance of the internal processes indicates progress towards success with the customer;

- Learning and growth: describe how people, technology, and organizational culture combine to support the strategy.

\subsection{Multi Criteria Decision Making (MCDM)}

A multicriteria decision problem consists of a situation in which there are at least two alternatives for choosing, to meet multiple (possibly conflicting) objectives, complex alternatives, important uncertainties, and significant consequences. These objectives are associated with variables that represent it and allow the evaluation of alternatives [15], [16].

MCDM is a process that seeks the best alternative among a series of alternatives considered adequate. MCDM methods are techniques to support decision-making given a finite number of alternatives, as well as a finite set of alternatives, as well as a set of objectives and criteria for evaluating the alternatives and their classification based on the level of satisfaction of the objectives [17]. One of the principles of multicriteria approaches is to help decision-makers to organize and synthesize this information in a way that they feel comfortable and confident about decision making [18].

The Analytic Hierarchy Process (AHP) method is one of the multi criteria decision making method which it has an additive aggregation method for modeling the decision maker's preferences. Proposed by Saaty, uses a peer-to-peer comparative procedure between alternatives of a given criterion using a nine-level semantic scale [15]. According to [19] the organization of objectives, attributes, problems in a hierarchical way provides an overview of complex relationships inherent in decision making and supports the decision-maker by assessing the problem at levels of the same order of magnitude from a comparison more homogeneous. For this purchase, the fundamental Saaty scale is used, which consists of a comparative judgment range that varies from "equal" to "extreme" (neutral, moderate preference, strong preference, very strong preference) corresponding to the numerical scale $(1,3,5,7,9)$ respectively.

[20] describes a way to decompose decision making as a definition of the problem and desired knowledge, structuring the decision hierarchy with the decision objective at 
the top, then in a broad perspective, passing through the intermediate levels to the lowest levels.

\section{MCDM and BSC integrated method to support the Digital Transformation}

The alignment and strategic mapping reflects the need for a prioritized portfolio and aligned with the company's strategy. This alignment can be done through a strategic mapping complemented by a value attribution model. To assemble the portfolio of innovative projects and programs guided by strategic mapping, it is important to define the related lines of action and validate whether these lines are in line with the company's strategy. Having defined the strategic objectives and lines of action, a value assignment model can be used in which weights are assigned to each strategic objective and scores for each project grouped in the lines of action [21].

Multicriteria methods to bring simplicity and transparency to the calculation of tradeoffs between evaluation criteria present in a BSC. The development of integrated use of multicriteria and BSC decision-making tools can be a key factor to provide success in the implementation and use of BSC by organizations [22].

The proposed method aims to support decision-making about digital transformation strategies, by pointing out performance drivers based on the organization's strategy (layer A), in which the BSC demonstrates enterprise vision in its organizational aspects in different perspectives and the technological map relates technological trends that can be applied in the rail freight sector. Layer B shows the application of the MCDM tool (AHP), which is divided into two stages and considers the strategic and technological elements of layer A as criteria. Finally, layer $\mathrm{C}$ shows the drivers for defining the digital transformation roadmap, or that is, the strategic and technological elements, obtained from the AHP, with greater relevance indicating themes in which the enterprise must allocate greater efforts of evolution.

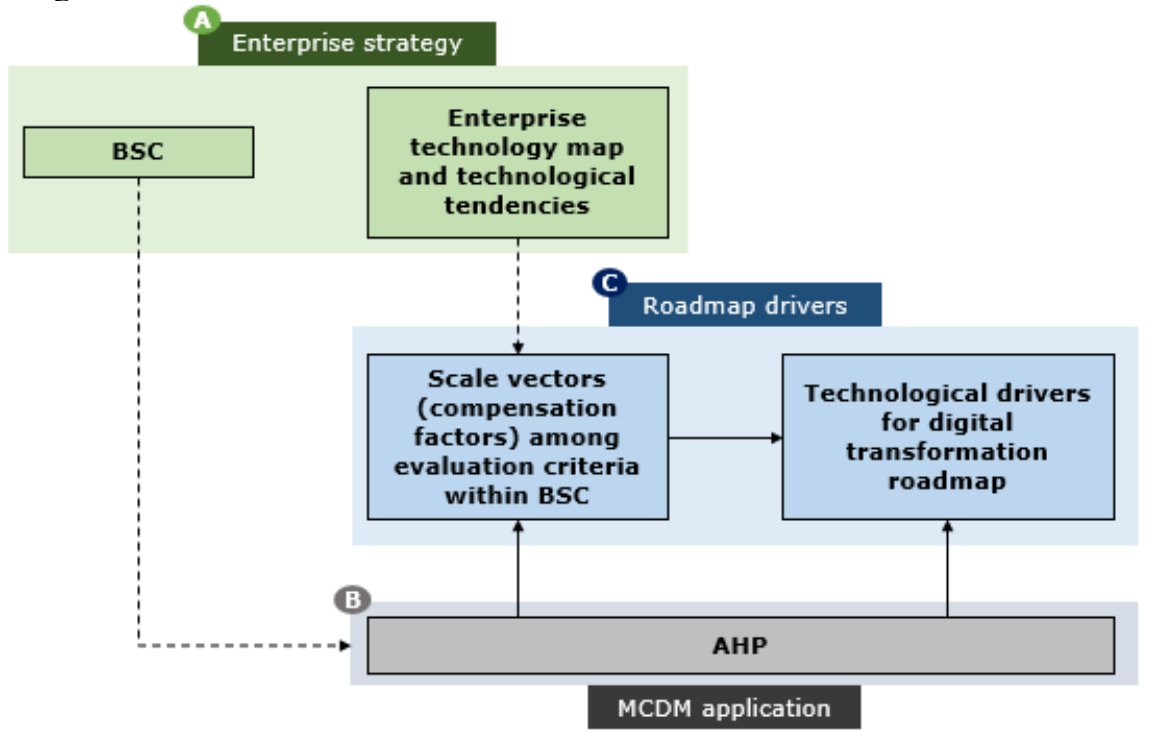

Figure 1. MCDM and BSC integrated method to support the Digital Transformation. 


\subsection{AHP analysis}

In this way, the AHP is shown as an adequate tool for assessing the impacts of each dimension on the company's strategy and of the technological elements in the strategic dimensions as the perceptions related to the impact of the BSC dimensions on the strategy are intangible for comparison and do not follow a specific standard, as recommended by [20], [23].

In this AHP analysis, the criteria considered are the BSC's dimensions. In the suggested description of [12]: Financial, customers, processes, and learning. These dimensions are not limiting, the addition of dimensions can be considered according to the needs of the company [14].

The alternatives are the technological elements, which can be obtained from mapping technological trends (eg.: foresight), sector-specific studies, business diagnostics, technological mapping, benchmarks with other companies and industries.

The application of the method allows the decision-maker to fragment a wide universe of possibilities, bringing greater clarity to how each of the alternatives (digital technologies) can collaborate with the company in obtaining the expected results, thus contributing to the construction of a digital transformation strategy adhering to the business strategy as a whole.

\subsection{AHP method execution}

The execution of the AHP method consists of 7 steps proposed by Saaty.

Step 1: Pairwise comparison between the dimensions, to generate the comparison matrix A, in which each $a_{i j}$ element represents the relative preference, according to the Saaty scale [19], [24], [25], the criteria of row i concerning the criteria of column $\mathrm{j}$.

Step 2: Matrix is normalized, according to equation 2, dividing each element of the matrix by the sum of its column::

$$
a_{i j}=\frac{a_{i j}}{\sum_{i=1}^{n} a_{i j}}, \text { where } \mathrm{j}=1,2,3, \ldots, \mathrm{n}
$$

Step 3: Eigenvector (relative importance or scale vector). It is an unconnected matrix of quantities, showing only the order of relative importance of the elements. For calculating the auto vector, Saaty exposes equation (3). This eigenvector shows the relative value of the elements, so the sum of its elements is always equal to 1 :

$$
W_{i}=\frac{\sum_{j=1}^{n} a_{i j}}{n} \text {, where } \mathrm{i}=1,2,3, \ldots, \mathrm{n}
$$

Step 4: Analysis of the consistency of the evaluation, indicates that for proper application, a matrix must present an uncertainty of less than $10 \%$. For this calculation, the sum of the weighted values $(\mathrm{W})$ is initially calculated using equation 4 :

$$
W=A * W_{i}
$$

Then, using equation 5, the eigenvalue of the obtained matrix $\left(\lambda_{\max }\right)$, is calculated, which consists of the arithmetic mean of dividing the sum of the weighted values (W) by the eigenvector $(\mathrm{Wi})$ : 
$\lambda_{\max }=\frac{1}{n} \sum_{i=1}^{n} \frac{[W]}{W_{i}}$

The consistency index is calculated by equation 6 :

$$
C I=\frac{\left(\lambda_{\max }-n\right)}{(n-1)}
$$

Finally, the consistency rate (CT) is given by equation (7), in a relationship between consistency index and random index (given by table 1):

$$
C T=\frac{(C I)}{(R I)} * 100 \%
$$

Table 1. RI index

\begin{tabular}{lllllllllll}
\hline $\mathbf{n}$ & $\mathbf{1}$ & $\mathbf{2}$ & $\mathbf{3}$ & $\mathbf{4}$ & $\mathbf{5}$ & $\mathbf{6}$ & $\mathbf{7}$ & $\mathbf{8}$ & $\mathbf{9}$ & $\mathbf{1 0}$ \\
\hline $\mathrm{RI}$ & 0.00 & 0.00 & 0.58 & 0.90 & 1.12 & 1.24 & 1.32 & 1.41 & 1.45 & 1.49 \\
\hline
\end{tabular}

\section{Case study}

For the validation and extraction of perceptions related to the applicability and contribution of the proposed method, a brief case study was carried out in a Brazilian freight railway industry. In carrying out this study, the evaluations present in the methodology were carried out by an innovation manager at the company and occurred in two phases. The first with the objective of evaluating the dimensions of the BSC about the company's moment and pointing out which factors are the most relevant to the company's vision. The second phase, on the other hand, took place by assessing the impact of digital technologies, previously mapped by the company, having at the end a technological direction to assist in the definition of the digital transformation strategy and roadmap. Subsequent topics detail the execution and results of the case study.

\subsection{BSC analysis by AHP}

The BSC of the company under study consists of 6 general dimensions, which were pairwise compared, to analyze the relative impact on the strategy and submitted to the AHP. At the level of amendments, 16 technological approaches were compared to read the relative strategic impact for the company. Figure 2 shows the hierarchy used in the application of AHP.

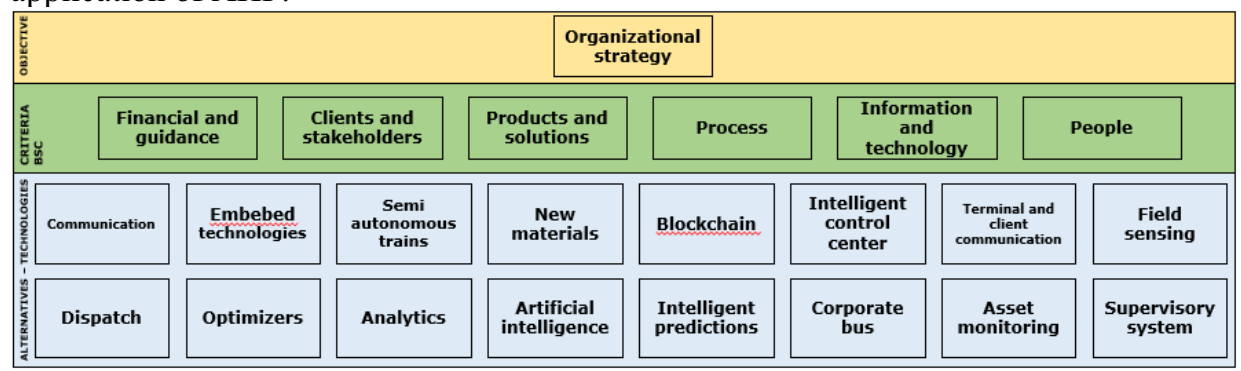

Figure 2. Enterprise BSC hierarchy dimensions. 
For the operationalization of the AHP method, the SuperDecision software was used, obtaining, as a result, for the assessment of the relative mapping of the BCS dimensions, the scale vector shown in table 2 .

Table 2. AHP scale vector for BSC dimensions.

\begin{tabular}{cc|cc}
\hline Dimension & Value & Dimension & Value \\
Clients and Stakeholders & 0,46145 & Financial and guidance & 0,07872 \\
People & 0,26174 & Information and technology & 0,04590 \\
Process & 0,12549 & Products and solutions & 0,02650 \\
\hline
\end{tabular}

From this result, it can be inferred that clients and stakeholders are the strategic dimension with the greatest impact for the company, being this the first driver for the construction of the digital transformation strategy.

The evaluation of alternatives consists of pairwise comparing each technological element to the dimensions of the BSC that are at the top level. For the demonstration in this study, the step was carried out for the dimension with the greatest impact (clients and stakeholders), resulting in table 3.

Table 3. AHP scale vector for technologies in customer and stakeholders dimension.

\begin{tabular}{|cc|cc|}
\hline Dimension & Value & Dimension & Value \\
\hline Asset monitoring & 0,18818 & Analytics & 0,03459 \\
Terminal and client & 0,17193 & Communication & 0,03408 \\
communication & & Intelligent predictions & 0,03401 \\
Supervisory & 0,08756 & Optimizers & 0,03311 \\
Blockchain & 0,08351 & Artificial intelligence & 0,03187 \\
Intelligent control center & 0,08192 & New materials & 0,01992 \\
Semi autonomous train & 0,08113 & Dispatch & 0,01474 \\
Field sensing & 0,05523 & Corporate bus & 0,00897 \\
\hline
\end{tabular}

This analysis shows that, for the strategic dimension of clients and stakeholders, from the perspective of the responding decision-maker, the technological factor with the greatest impact is asset monitoring.

\section{Discussion}

The construction of the proposed framework and its application in a case study allows us to observe that the proposal is positive to generate drivers and discussions related to the construction of a strategy and roadmap of digital transformation adhering to the company's strategy, providing greater clarity to decision-makers on the approaches of greater importance. impact and trend of positive results.

Asset monitoring makes it possible to optimize maintenance based on the identification of behaviors and variations in assets, which makes it possible to prevent accidents, unplanned delays, and business losses. Thus increasing overall efficiency and reducing operating costs [26]. Blockchain can bring credibility and transparency in faster, more effective and traceable commercial relations, reducing errors, costs and risk of fraud [27]. Another example is the semi-autonomous train that impacts fuel economy and emission of pollutants (10\% reduction). Generating operational cost reduction and cleaner transportation for clients [28].

This analysis, when taken to a group of decision-makers, generates different personal views and discussions, since they are interpretations subject to subjectivity and 
that this is intrinsic to multicriteria methods. Therefore, it is important that there is a diversity of decision-makers participating in the analysis and that all results are considered, either through rounds of negotiation until a common agreement is reached, or through the use of mathematical equations that take into account different perceptions.

Although the proposal brings clarity to decision-makers to technological elements, for a holistic view of strategic impact, it is also important to observe and map the operational processes so that, from a diagnosis of digital matrices in each phase of the process, it is possible to improve the targeting of technologies that provide greater impact and adherence to the company's strategy. Finally, the application of AHP involving a high number of alternatives generates high-order comparison matrices which impact a large volume of comparisons pair by pair for decision-makers, this can take a lot of time and difficult organization of schedules and engagement of people. Alternatives like simplified version purpose by [29] or revision of the hierarchical structure segmenting the evaluative space can increase the attractiveness of the AHP method.

\section{Conclusion}

Digital transformation is an increasingly explicit and multidisciplinary need for organizations in general. Technological evolution in an exponential way requires quick decisions and the right strategies so that companies can achieve their goals and increase their competitiveness in the digital economy.

The strategy for digital transformation must have a relevant role and adhere to the corporate strategy, for these decision-makers must have clarity of where they want to go and how technology can drive this movement when defining their action plans. However, this is one of the biggest challenges faced by organizations, which can lead to inconsistent decisions and waste of resources.

Organizations and sectors of the traditionalist industry impose an even greater challenge on their managers, as they have a lower level of maturity in the digitalization of their operations and demand a rapid evolution in this sense to remain competitive. The railway industry, characterized as a traditionalist industry, is of great relevance for economic and social development and functions as an ecosystem of dependent operations in which digitalization is essential to expand operational capacity and improve its competitiveness.

The MCDM are an important tool to help the construction of a holistic vision and building strategies for digital transformation, even in the most traditionalist industries that have shorter maturity and greater complexity, as occurs in the railway industry.

The proposed framework, based on the sum of the BSC and the AHP, allows the deconstruction of strategic and technological elements and analysis "in parts", bringing to the decision-makers greater clarity and reasoning in their analysis, making the strategic directions for building a roadmap of actions digitalization programs that are adherent to the company's strategic objectives.

Future work may expand the application of the tool to validate the proposal, as well as use outranking mcdm tools to direct the roadmap of actions.

\section{References}



J. Reis, M. Amorim, N. Melao, and P. Matos, Digital Transformation: A Literature Review and Guidelines for Future Digital Transformation: A Literature Review and Guidelines for Future Research, 10th Eur. Conf. Inf. Syst. Manag. Acad. Conf. Publ. Ltd., 2016, Vol. 1, No. March, pp. 2028, doi: 10.1007/978-3-319-77703-0.

[3] I. Pihir, K. Tomičić-Pupek, and M. Tomičić Furjan, Digital transformation playground, J. Inf. Organ. Sci., 2019, Vol. 43, No. 1, pp. 33-48, doi: 10.31341/jios.43.1.3.

[4] S. Berghaus and A. Back, Stages in Digital Business Transformation: Results of an Empirical Maturity Study, MCIS 2016 Proc., 2016, Vol. 22.

[5] S. Nadkarni and R. Prügl, Digital transformation: a review, synthesis and opportunities for future research, Management Review Quarterly, 2021, Vol. 71, pp. 233-341.

[6] M. Güler and G. Büyüközkan, Analysis of digital transformation strategies with an integrated fuzzy AHP-axiomatic design methodology, IFAC-PapersOnLine, 2019, Vol. 52, No. 13, pp. 1186-1191, doi: 10.1016/j.ifacol.2019.11.359.

[7] R. Teichert, Digital transformation maturity: A systematic review of literature, Acta Univ. Agric. Silvic. Mendelianae Brun., 2019, Vol. 67, No. 6, pp. 1673-1687, doi: 10.11118/actaun201967061673.

[8] M. Jabloński and A. Jabloński, Social factors as a basic driver of the digitalization of the business models of railway companies, Sustain., 2019, Vol. 11, No. 12, pp. 1-29, doi: 10.3390/su10023367.

[9] M. Jabloński and A. Jabloński, Social Perspectives in Digital Business Models of Railway Enterprises, Energies, 2020, 13(23), 6445.

[10] V. Jägare, R. Karim, P. Söderholm, P.-O. Larsson-Kråik, and U. Juntti, Change management in digitalised operation and maintenance of railway, Int. Heavy Haul Assoc. STS 2019 Conf. , 2019, pp. 904-911.

[11] N.N., Digital Trends in the Rail Sector, UNIFE-The European Rail Supply Industry Association, 2019, https://www.unife.org/wp-content/uploads/2021/02/Digital-trends-in-the-Rail-sector.pdf.

[12] R. S. Kaplan and D. P. Norton, Strategy Maps, Harvard Business School Press, Boston, 2004.

[13] F. Frezatti, D.D.S. Bido, A.P.C. Da Cruz, and M.J.D.C. Machado, O Papel Do Balanced Scorecard Na Gestão Da Inovação, Rev. Adm. Empres., 2014, Vol. 54, No. 4, pp. 381-392, doi: 10.1590/s0034759020140404.

[14] R. S. Kaplan and David Norton, The Balanced Scorecard: Translating Strategy into Action, Harvard Business School Press, Boston, 1996.

[15] A.T. de Almeida, Processo de decisão nas organizações: construindo modelos de decisão multicritério. Editora Atlas S.A., Sao Paulo, 2013.

[16] G. S. Parnell, T. A. Bresnick, S. N. Tani, and E. R. Johnson, Handbook of decision analysis, Wiley, Hoboken, 2013.

[17] C. M. Rodrigues, F. Deschamps, E. de F. R. Loures, J. M. A. P. Cestari, and I. H. de Freitas, Digital Transformation Project Portfolio Selection/Prioritization: Literature Review and Future Directions, IJCIEOM 2019, LNMUINEN, 2020, pp. 282-292.

[18] V. Belton And T. J. Stewart, Multiple Criteria Decision Analysis An Integrated Approach. 201AD.

[19] T.L. Saaty, How to make a decision: The Analytic Hierarchy Process, Eur. J. Oper. Res., 1990, Vol. 48, pp. 9-26, doi: 10.1007/978-1-4614-3597-6_1.

[20] T.L. Saaty, Decision making with the analytic hierarchy process, Int. J. Serv. Sci., 2008, Vol. 1, No. 1, pp. 83-98, doi: 10.1504/ijssci.2008.017590.

[21] A. Tauvy et al., Fomento à inovação: Da ideia ao recurso. Inventta+bgi, 2016.

[22] F.A.F. Ferreira, Measuring trade-offs among criteria in a balanced scorecard framework: Possible contributions from the multiple criteria decision analysis research field, J. Bus. Econ. Manag., 2013, Vol. 14, No. 3, pp. 433-447, doi: 10.3846/16111699.2011.631744.

[23] T.L. Saaty, To Make a Decision : The Analytic, Interfaces (Providence), 1994, vol. 24, no. 6, pp. 1943.

[24] T.L. Saaty, An Exposition of the AHP in Reply to the Paper 'Remarks on the Analytic Hierarchy Process," Manage. Sci. , 1990, Vol. 36, pp. 259-268.

[25] T.L. Saaty, How to Make a Decision: The Analytic Hierarchy Process, J. Oper. Res. , 1990, Vol. 48, pp. $9-26$.

[26] A. Thaduri, D. Galar, and U. Kumar, Railway assets: A potential domain for big data analytics," Procedia Comput. Sci., vol. 53, no. 1, pp. 457-467, 2015, doi: 10.1016/j.procs.2015.07.323.

[27] N. Wognum, C. Bil, F. Elgh, M.Peruzzini, J. Stjepandić, W. Verhagen, Transdisciplinary engineering research challenges, Advances in Transdisciplinary Engineering, 2018, Vol. 7, pp. 753-762.

[28] J. Huang, Y. Deng, Q. Yang, and J. Sun, An Energy-Efficient Train Control Framework for Smart Railway Transportation, IEEE Trans. Comput., 2016, Vol. 65, No. 5, pp. 1407-1417, doi: 10.1109/TC.2015.2500565.

[29] J.E. Leal, AHP-express: A simplified version of the analytical hierarchy process method, MethodsX, 2020, Vol. 7, 100748, doi: 10.1016/j.mex.2019.11.021. 